\title{
COMPOSTO DE ÁGUAS RESIDUÁRIAS DE SUINOCULTURA NA PRODUÇÃO DE MUDAS DE ESPÉCIES FLORESTAIS
}

\author{
Clovis Orlando Da Ros ${ }^{1 *}$, Marcela de Melo Torchelsen ${ }^{1}$, Lucindo Somavilla $^{1}$, Rodrigo Ferreira da Silva ${ }^{1}$, \\ Alexandre Couto Rodrigues ${ }^{2}$

\footnotetext{
${ }^{1 *}$ Universidade Federal de Santa Maria, Departamento de Ciências Agronômicas e Ambientais, Frederico Westphalen, Rio Grande do Sul, Brasil - clovisdaros@gmail.com, mtorchelsen@ hotmail.com, lucindosomavilla@ hotmail.com, rofesil@bol.com.br.

${ }^{2}$ Universidade Federal de Santa Maria, Departamento de Engenharia e Tecnologia Ambiental, Frederico Westphalen, Rio Grande do Sul, Brasil - coutoalexandre@yahoo.com.br.
}

Recebido para publicação: 20/06/2017 - Aceito para publicação: 04/01/2018

\begin{abstract}
Resumo
O crescimento e a qualidade das mudas de espécies florestais estão relacionados ao tipo de substrato. Assim, objetivou-se quantificar a emergência das plântulas, o crescimento e a qualidade de mudas de três espécies florestais com diferentes proporções de composto de águas residuárias de suinocultura (CARS) misturado ao substrato comercial (SC). O delineamento experimental foi inteiramente casualizado, com quatro repetições, em arranjo fatorial 3 x 5: três espécies florestais (Eucalyptus benthamii, Toona ciliata e Khaya ivorensis) e cinco proporções de CARS adicionadas ao SC (0, 25, 50, 75 e 100\%). Foram avaliados o percentual de emergência das plântulas e o crescimento em altura das mudas. A qualidade das mudas foi avaliada por meio de relações entre altura, diâmetro do colo e massa seca das mudas. Os resultados foram submetidos à análise da variância a 5\% de probabilidade de erro e ajustados a modelos de regressão polinomial quando significativo o fator proporção de CARS adicionadas no SC. A substituição total ou parcial do SC por CARS não alterou a emergência das plântulas, o crescimento e a qualidade das mudas das espécies florestais. A produção de mudas das três espécies florestais pode ser realizada com CARS obtido através de compostagem em unidades mecanizadas, em substituição parcial ou total ao SC.

Palavras-chave: altura, qualidade de mudas, Eucalyptus benthamii, Toona ciliata, Khaya ivorensis.
\end{abstract}

\begin{abstract}
Swine wastewater compound in the production of forest species. The growth and quality of forest species seedlings are related to the type of substrate. The objective of this study was to quantify the seedling emergence, growth and quality of three forest species with different ratios of swine wastewater composed mixed with commercial substrate. The experimental design was completely randomized, with four replications in a $3 \times 5$ factorial arrangement: three forest species (Eucalyptus benthamii, Toona ciliata and Khaya ivorensis) and five swine wastewater composed proportions added in commercial substrate $(0,25,50,75$ and $100 \%)$. The emergence percentage and the growth in height of the seedlings were evaluated. The quality of the seedlings was evaluated by means of relationships among height, diameter of the colon and dry mass of the seedlings. The results were subjected to analysis of variance at $5 \%$ probability of error and adjusted regression models when the factor proportion of swine wastewater composed added in commercial substrate was significant. The total or partial replacement of commercial substrate by swine wastewater composed did not alter the germination, growth and quality of the forest species seedlings. The production of seedlings of the three forest species can be performed with swine wastewater composed obtained in mechanized composting, in partial or total replacement to the commercial substrate.

Keywords: seedling height, seedling quality, Eucalyptus benthamii, Toona ciliata, Khaya ivorensis.
\end{abstract}

\section{INTRODUÇÃO}

Espécies florestais exóticas, como o eucalipto, cedro australiano e mogno africano, apresentam alto potencial de produção de madeira nas condições edafoclimáticas do Brasil. O eucalipto se destaca por sua maior área de cultivo em razão das boas características de adaptabilidade, crescimento e produtividade (ABRAF, 2013). O cedro australiano e, principalmente, o mogno africano são espécies florestais introduzidas mais recentemente no Brasil (PINHEIRO et al., 2011; VILELA; STEHLING, 2012) e, juntamente com o eucalipto, carecem de informações sobre a produção de mudas quando envolve novos tipos de substratos.

A produção de mudas é a primeira etapa no processo de cultivo de espécies florestais. A qualidade das mudas reflete diretamente no potencial de produção de madeira, sendo afetada pela qualidade das sementes, sistema de produção, condições climáticas, pragas e doenças, nutrição mineral e tipo de substrato (KRATZ; WENDLING, 2013; DA ROS et al., 2015). Os atributos físicos e químicos dos substratos são os principais fatores que condicionam o crescimento de mudas com qualidade. Em sistemas de produção de mudas

FLORESTA, Curitiba, PR, v. 48, n. 1, p. 103-112, jan./marc. 2018.

Da Ros. C. O. et al.

ISSN eletrônico 1982-4688

DOI: $10.5380 /$ rf.v48 i1.53346 
com tubetes em casa de vegetação com irrigação periódica, a qualidade física dos substratos, muitas vezes, sobrepõe à química. Neste sistema, ocorre significativa perda de nutrientes por lixiviação e, muitas vezes, a quantidade de nutrientes presentes no substrato não atende à demanda nutricional das plantas sem a adição suplementar de fertilizante mineral (DA ROS et al., 2017). Assim, a produção de mudas com qualidade em tubetes necessita de adição periódica de nutrientes ou uso de fertilizantes de liberação lenta (MUNIZ et al., 2013).

Apesar da legislação sobre especificações, garantias e tolerâncias (BRASIL, 2009), a qualidade dos substratos apresenta variação nos atributos químicos e físicos em função da combinação dos tipos de materiais utilizados na sua composição, destoando das faixas ideais de aeração e de retenção de água, além de apresentar alta alcalinidade e excesso de sais em sua composição (SCHAFER et al. 2015). Essa variação não garante a mesma qualidade de mudas, indicando que é necessário escolher adequadamente o substrato em função da espécie florestal e do tipo de sistema de produção de mudas. Variações na emergência das plântulas e no crescimento das mudas são relatadas em diversos estudos com diferentes tipos de substratos (BRUGNARA et al., 2014; DELARMELINA et al., 2014; DA ROS et al., 2015).

A aquisição de substratos comerciais gera um custo na produção de mudas e, muitas vezes, o uso de materiais alternativos e mais baratos é uma opção em função da disponibilidade de compostos orgânicos na região próxima à locação do viveiro florestal (TRAZZI et al., 2013; MENDONÇA et al., 2014). Nas regiões produtoras de suínos, o uso do sistema de tratamento dos dejetos por processo de compostagem vem crescendo. Esse sistema de tratamento utiliza os dejetos líquidos provenientes da produção de suínos, denominados de águas residuárias. As águas residuárias são compostas por fezes e urina dos animais, água provinda de bebedouros e decorrente da lavagem das instalações, restos de ração, pelos e afins, em combinação com um composto rico em carbono. A compostagem desses materiais é realizada em leiras, formadas por adição de serragem ou maravalha e de água residuária provenientes da criação de suínos em unidades mecanizadas de compostagens, conforme descrita por Serpa Filho et al. (2013).

Estudos mostram que o composto gerado por esse sistema de tratamento pode ser utilizado como substrato para a produção de mudas, porém sem uma definição clara sobre se pode ou não ser usado em substituição parcial ou total ao substrato comercial em diferentes espécies florestais (BRUGNARA et al., 2014; DA ROS et al., 2017). Com base nesse contexto, o objetivo do trabalho foi quantificar a emergência, o crescimento e a qualidade de mudas de eucalipto, cedro australiano e mogno africano, com diferentes proporções de composto de águas residuárias de suinocultura adicionadas ao substrato comercial.

\section{MATERIAL E MÉTODOS}

O experimento foi conduzido no período de novembro de 2015 a março de 2016 no Viveiro Florestal da Universidade Federal de Santa Maria, campus de Frederico Westphalen (RS), localizado na latitude de $27^{\circ} 23^{\prime} 46^{\prime \prime}$ e longitude de 53²5'37', com elevação média de 477 metros do nível do mar. O clima local é subtropical úmido com verão quente, tipo Cfa, com temperaturas máximas maiores ou iguais $22{ }^{\circ} \mathrm{C}$ e mínimas entre -3 e $18{ }^{\circ} \mathrm{C}$ nos meses mais frios. A precipitação média anual é de 1.900 a $2.200 \mathrm{~mm}$ (ALVARES et al., 2013).

$\mathrm{O}$ delineamento experimental foi o inteiramente casualizado, com quatro repetições no esquema fatorial 3 x 5: três espécies florestais e cinco proporções de composto de águas residuárias de suinocultura (CARS) adicionadas ao substrato comercial (SC). A unidade experimental foi composta de seis tubetes de $170 \mathrm{~cm}^{3}$, totalizando 24 tubetes por tratamento.

As espécies florestais utilizadas foram o eucalipto (Eucalyptus benthamii Maiden et Cambage), cedro australiano (Toona ciliata M. Roem var. australis) e mogno africano (Khaya ivorensis A. Chev.). As sementes de eucalipto (peletizadas) foram provenientes da Bentec ${ }^{\circledR}$ - Sementes, Insumos e Tecnologia, Rio do Sul (SC), safra 2013; de cedro australiano da Sementes Caiçara ${ }^{\circledR}$, Brejo Alegre (SP), safra 2015; e do mogno africano do Instituto Brasileiro de Florestas (IBF), Curitiba (PR), safra 2015.

As proporções de CARS adicionadas no SC foram 0, 25, 50, 75 e 100\%, com base no volume $\left(\mathrm{v} \mathrm{v}^{-1}\right)$. Antes da realização das misturas dos compostos para formar os tratamentos, o CARS foi seco ao ar, na sombra, com o objetivo de diminuir a umidade e facilitar a homogeneização com o SC. O processo de secagem diminuiu a umidade de 0,76 para $0,68 \mathrm{~g} \mathrm{~g}^{-1}$. O SC foi da marca Tecnomax ${ }^{\circledR}$, composto a base de casca de pinus compostada, carvão vegetal, cinza, vermiculita e cama de aves. O CARS foi obtido de uma unidade de produção de suínos localizada no município de Rodeio Bonito, na região do Alto Uruguai (RS). A unidade contempla a produção de suínos desde a produção de leitões, crescimento, até a terminação, totalizando 9.800 cabeças.

O sistema de tratamento das águas residuárias pelo processo de compostagem utilizada na unidade de produção de suínos foi realizado através da compostagem mecanizada, semelhante à descrita por Serpa Filho et al. (2013). As unidades são instaladas em galpões cobertos por folhas de telhas translúcidas, a fim de garantir a passagem de luz solar e melhorar o processo de maturação do composto, com piso de concreto e partições longitudinais, formando oito linhas (leiras de compostagem) por onde ocorre a passagem da máquina de compostagem. As leiras de compostagem são formadas por adição de serragem de madeira (1,2 m de altura) que 
recebem águas residuárias por tubulações suspensas a cada oito dias em sistema alternado de duas leiras. O revolvimento das leiras é realizado por um sistema de hastes helicoidais em intervalos de dois dias, incluindo o dia de recebimento da água residuária.

As amostras do CARS foram coletadas em julho de 2015 em uma leira que estava no estágio final de estabilização (em torno de seis meses), sendo amostradas, aleatoriamente, em cinco pontos. O material de cada ponto de amostragem foi revolvido e homogeneizado, colocado em sacos plásticos para o transporte e, posteriormente, secos ao ar, na sombra sobre uma lona plástica, por 30 dias.

Antes da implantação do experimento, foram caracterizados os atributos físicos e químicos do CARS e do SC. A densidade com base na massa seca a $65^{\circ} \mathrm{C}$, a capacidade de retenção de água a $10 \mathrm{~cm}$ de coluna de água $(10 \mathrm{hPa})$, o pH e a condutividade elétrica na mistura substrato e água na proporção 1:5 foram quantificados com base na metodologia para substratos descrita pela instrução normativa ${ }^{\circ} 17$ do Ministério da Agricultura, Pecuária e Abastecimento (BRASIL, 2007). A porosidade total, macro e microporosidade foram caracterizadas conforme Embrapa (2011). O espaço de aeração foi calculado por meio da diferença entre a porosidade total e a capacidade de retenção de água sob tensão de $10 \mathrm{hPa}$.

Os teores totais de nitrogênio $(\mathrm{N})$, fósforo $(\mathrm{P})$ e potássio $(\mathrm{K})$ foram extraídos por meio de digestão com $\mathrm{H}_{2} \mathrm{SO}_{4}$ concentrado, usando $0,2 \mathrm{~g}$ de amostras secas a $65^{\circ} \mathrm{C}$. Os teores disponíveis de $\mathrm{P}$ e $\mathrm{K}$ foram extraídos pela solução Mehlich-1 $\left(\mathrm{H}_{2} \mathrm{SO}_{4}\right.$ 0,0125 mol L-1 $\left.+\mathrm{HCl} \mathrm{0,05} \mathrm{mol} \mathrm{L-1}\right)$ e os teores de $\mathrm{N}$, na forma de amônio $\left(\mathrm{N}^{-} \mathrm{NH}_{4}^{+}\right)$e de nitrato $\left(\mathrm{N}_{-} \mathrm{NO}_{3}^{-}\right)$, foram extraídos pela solução $\mathrm{KCl} 1 \mathrm{~mol} \mathrm{~L}-1$, usando amostras "in natura" para evitar possíveis perdas, principalmente de $\mathrm{N}$, durante o processo de manuseio e secagem das amostras. A quantificação de $\mathrm{N}$ ocorreu por meio de destilação (semi-micro Kjeldahl) e titulação com ácido sulfúrico; de P por espectrofotometria; e de K por fotometria de chamas, conforme descritos em Silva (2009). O carbono orgânico foi extraído pelo método Walkley-Black, descrito em Silva (2009).

As espécies florestais foram semeadas em 01/11/2015, usando três sementes por tubete e, após 40 dias da emergência, foi mantida uma plântula por tubete. A adubação de semeadura foi realizada com fertilizante de liberação lenta (Osmocote®), fórmula NPK (15-9-12), na dose de 7,0 $\mathrm{kg} \mathrm{m}^{-3}$ de substrato. Não foi usada adubação de cobertura. O regime de irrigação foi de $8 \mathrm{~mm}$ diários, subdivididos em quatro turnos de rega por sistema de microaspersão automatizado.

A avaliação da emergência das plântulas, por meio de observação visual e registro das plântulas emergidas, foi realizada em intervalos de quatro dias até 36 dias da semeadura, totalizando nove avaliações. $\mathrm{O}$ crescimento das mudas foi quantificado por meio da altura $(\mathrm{H})$ da parte aérea, medida com régua graduada do colo das mudas até o ápice caulinar, aos 65, 94 e 128 dias após a semeadura.

Ao final da condução do experimento (128 dias) foi avaliado o diâmetro do colo (DC), medido com paquímetro digital com precisão de $0,01 \mathrm{~mm}$; a massa seca do sistema radicular (MSR) e da parte aérea (MSPA), sendo ambas as frações separadas na região do colo da muda e submetidas à secagem em estufa a $65 \pm 1{ }^{\circ} \mathrm{C}$ até massa constante, e a massa seca total (MST), pela soma da MSR e MSPA. Com base nesses parâmetros, foi quantificada a qualidade das mudas pelas relações entre H/DC, H/MSPA e MSPA/MSR e pelo índice de qualidade de Dickson (IQD), que considerou a robustez e o equilíbrio da distribuição da biomassa nas mudas e foi calculado por meio da fórmula: IQD = [MST/(H/DC + MSPA/MSR) $]$ (DICKSON et al., 1960).

Os dados foram transformados em $\sqrt{(x+1)}$, quando necessário, para normalizar a distribuição do erro e submetidos à análise da variância. Quando o teste $\mathrm{F}$ da análise da variância para os tratamentos foi significativo ( $\mathrm{p} \leq 0,05)$, as médias dos tratamentos qualitativos (espécies) foram comparadas pelo teste de Tukey e os tratamentos qualitativos quantitativos (proporção de CARS adicionado ao SC) ajustados por meio de regressão polinomial, ambos a 5\% de probabilidade de erro. Aos resultados da análise dos atributos químicos e físicos dos substratos, foram ajustados modelos de regressão com base na proporção de CARS adicionado ao SC.

\section{RESULTADOS}

A análise de regressão polinomial, com base na proporção de CARS adicionado ao SC, ajustou a equação de regressão linear para todos os atributos físicos e químicos dos substratos analisados, com alto valor de coeficiente de correlação (Tabela 1). Com exceção da densidade seca e da relação C/N, os demais atributos aumentaram com a proporção de CARS adicionado ao SC. 
Tabela 1. Atributos físicos e químicos dos substratos usados no cultivo das mudas em função da proporção de composto de dejetos de suínos (CARS) adicionado no substrato comercial (SC).

Table 1. Physical and chemical attributes of the substrates used to grow the seedlings as a function of the proportion of swine wastewater compound added in the commercial substrate.

\begin{tabular}{|c|c|c|c|c|c|c|c|}
\hline \multirow[t]{2}{*}{ Atributos $^{(1)}$} & \multicolumn{5}{|c|}{ Proporção de CARS adicionado ao SC (\%) } & \multirow[t]{2}{*}{$\begin{array}{l}\text { Equação de } \\
\text { regressão }\end{array}$} & \multirow[t]{2}{*}{$\mathbf{R}^{2}$} \\
\hline & $\mathbf{0}$ & 25 & 50 & 70 & 100 & & \\
\hline & \multicolumn{7}{|c|}{ 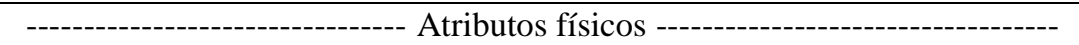 } \\
\hline Umidade volumétrica $\left(\mathrm{g} \mathrm{ml}^{-1}\right)$ & 0,29 & 0,31 & 0,32 & 0,33 & 0,35 & $\hat{y}=0,0006 x+0,29$ & 0,98 \\
\hline Umidade gravimética $\left(\mathrm{g} \mathrm{g}^{-1}\right)$ & 0,51 & 0,52 & 0,57 & 0,62 & 0,68 & $\hat{y}=0,0018 x+0,49$ & 0,96 \\
\hline Densidade seca $\left(\mathrm{Mg} \mathrm{m}^{-3}\right)$ & 0,27 & 0,26 & 0,23 & 0,20 & 0,17 & $\hat{y}=-0,001 x+0,29$ & 0,98 \\
\hline Porosidade total $\left(\mathrm{m}^{3} \mathrm{~m}^{-3}\right)$ & 0,76 & 0,79 & 0,82 & 0,83 & 0,85 & $\hat{y}=0,0009 x+0,77$ & 0,97 \\
\hline Microporosidade $\left(\mathrm{m}^{3} \mathrm{~m}^{-3}\right)$ & 0,36 & 0,38 & 0,39 & 0,40 & 0,41 & $\hat{y}=0,0005 x+0,36$ & 0,96 \\
\hline Macroporosidade $\left(\mathrm{m}^{3} \mathrm{~m}^{-3}\right)$ & 0,40 & 0,41 & 0,43 & 0,43 & 0,44 & $\hat{y}=0,0004 x+0,40$ & 0,92 \\
\hline $\mathrm{CRA}_{10}\left(\mathrm{~m}^{3} \mathrm{~m}^{-3}\right)$ & 0,50 & 0,52 & 0,53 & 0,54 & 0,55 & $\hat{y}=0,0005 x+0,50$ & 0,96 \\
\hline Espaço de aeração $\left(\mathrm{m}^{3} \mathrm{~m}^{-3}\right)$ & 0,26 & 0,27 & 0,29 & 0,29 & 0,30 & $\hat{y}=0,0004 x+0,26$ & 0,93 \\
\hline \multicolumn{8}{|c|}{ Atributos químicos } \\
\hline $\mathrm{N}_{\text {total }}\left(\mathrm{g} \mathrm{kg}^{-1}\right)$ & 5,02 & 15 & 8,90 & 12,32 & 14,76 & $36 x+4,70$ & 0,99 \\
\hline $\mathrm{N}_{\text {disponível }}\left(\mathrm{N}-\mathrm{NH}_{4}^{+}\right)\left(\mathrm{mg} \mathrm{kg}^{-1}\right)$ & 7,2 & 35,2 & 67,8 & 135,1 & 176,7 & $\hat{y}=1,7556 x-3,38$ & 0,97 \\
\hline $\mathrm{N}_{\text {disponível }}\left(\mathrm{N}-\mathrm{NO}_{3}^{-}\right)\left(\mathrm{mg} \mathrm{kg}^{-1}\right)$ & 2,5 & 19,1 & 31,5 & 61,2 & 132,6 & $\hat{y}=1,2092 x-11,08$ & 0,87 \\
\hline $\mathrm{P}_{\text {total }}\left(\mathrm{g} \mathrm{kg}^{-1}\right)$ & 2,98 & 3,35 & 4,28 & 5,33 & 6,48 & $\hat{y}=0,0359 x+2,69$ & 0,97 \\
\hline $\mathrm{P}_{\text {disponível }}\left(\mathrm{g} \mathrm{kg}^{-1}\right)$ & 1,11 & 1,59 & 2,08 & 2,79 & 3,90 & $\hat{y}=0,0271 x+0,94$ & 0,96 \\
\hline $\mathrm{K}_{\text {total }}\left(\mathrm{g} \mathrm{kg}^{-1}\right)$ & 4,55 & 5,68 & 6,15 & 6,95 & 8,15 & $\hat{y}=0,0339 x+4,60$ & 0,98 \\
\hline $\mathrm{K}_{\text {disponível }}\left(\mathrm{g} \mathrm{kg}^{-1}\right)$ & 1,95 & 2,94 & 3,90 & 5,40 & 7,20 & $\hat{y}=0,0518 x+1,69$ & 0,98 \\
\hline Carbono orgânico $\left(\mathrm{g} \mathrm{kg}^{-1}\right)$ & 172,3 & 229,9 & 248,0 & 303,6 & 350,5 & $\hat{y}=1,72 x+174,84$ & 0,98 \\
\hline Relação C/N & 34,33 & 32,17 & 27,87 & 24,65 & 23,75 & $\hat{y}=-0,115 x+34,29$ & 0,96 \\
\hline Cond. elétrica $(1: 5)\left(\mathrm{dS} \mathrm{m}^{-1}\right)$ & 1,05 & 1,23 & 1,36 & 1,43 & 1,54 & $\hat{y}=0,0047 x+1,09$ & 0,97 \\
\hline $\mathrm{pH}_{\text {água }}(1: 5)$ & 6,0 & 6,0 & 6,1 & 6,5 & 7,2 & $\hat{y}=0,0116 x+5,78$ & 0,80 \\
\hline
\end{tabular}

${ }^{(1)} \mathrm{CRA}_{10}$ : capacidade de retenção de água a $10 \mathrm{~cm}$ de coluna de água.

As equações de regressão das proporções de CARS adicionado ao SC indicaram variação dos atributos físicos entre 0,19 e $0,29 \mathrm{Mg} \mathrm{m}^{-3}$ na densidade seca; 0,77 a $0,86 \mathrm{~m}^{3} \mathrm{~m}^{-3}$ na porosidade total; 0,36 a $0,41 \mathrm{~m}^{3} \mathrm{~m}^{-3} \mathrm{na}^{-3}$ microporosidade; 0,40 a $0,44 \mathrm{~m}^{3} \mathrm{~m}^{-3}$ na macroporosidade; 0,50 a $0,55 \mathrm{~m}^{3} \mathrm{~m}^{-3}$ na capacidade de retenção de água a tensão de $10 \mathrm{hPa}$; e 0,26 a $0,30 \mathrm{~m}^{3} \mathrm{~m}^{-3}$ no espaço de aeração (Tabela 1). Os teores totais de nutrientes no substrato variaram entre 4,70 e 14,56 $\mathrm{g} \mathrm{kg}^{-1}$ de nitrogênio; 2,69 e 6,28 $\mathrm{g} \mathrm{kg}^{-1}$ de fósforo; e 4,60 e 7,99 $\mathrm{g} \mathrm{kg}^{-1}$ de potássio. A variação da condutividade elétrica foi de 1,09 a $1,56 \mathrm{dS} \mathrm{m}^{-1}$ e do $\mathrm{pH}$ de 5,78 a 6,94.

A análise da variância de todos os parâmetros de crescimento e de qualidade das mudas avaliados não mostrou interação significativa entre o fator espécie e o fator proporção de CARS adicionado ao SC (Tabela 2). Esse resultado mostra que proporção de CARS adicionado ao SC interagiu de forma semelhante na emergência das plântulas, crescimento e qualidade das mudas nas três espécies florestais. Com relação aos efeitos principais, o teste $\mathrm{F}$ da análise da variância indicou ausência de significância em todos os parâmetros avaliados para a adição crescente de CARS ao SC. Somente houve significância do teste F para o efeito das espécies florestais.

A emergência das plântulas do eucalipto e do cedro australiano iniciou a partir de oito dias da semeadura. Para o mogno africano, foi necessário o dobro do tempo (Figura 1). Ao final do período avaliado (36 dias), o percentual de plântulas emergidas, média dos substratos, foi maior no cedro australiano $(87,1 \%)$ e no eucalipto $(84,4 \%)$, em comparação com o mogno africano $(47,1 \%)$.

A altura das mudas, nas três épocas avaliadas, apresentou diferença significativa entre as espécies florestais, destacando o eucalipto, seguido do cedro australiano e do mogno africano com 59,1; 36,3 e $23,7 \mathrm{~cm}$, respectivamente, aos 128 dias da semeadura (Figura 2). O diâmetro do colo e as massas secas da parte aérea e radicular também apresentaram diferenças significativas entre as espécies, destacando o cedro australiano com maior diâmetro de colo e maior massa seca radicular, e o eucalipto e o cedro australiano com maior massa seca da parte aérea (Tabela 3). 
Tabela 2. Probabilidade do teste $\mathrm{F}$ da análise da variância dos parâmetros de emergência das plântulas, de crescimento e de qualidade das mudas para o fator espécie, fator proporção do composto de águas residuárias de suinocultura (CARS) adicionado ao substrato comercial (SC) e interação entre os dois fatores.

Table 2. Probability of the test $\mathrm{F}$ of variance analysis of the seedling emergence, growth and quality parameters for the species factor, factor proportion of the swine wastewater compound added to the commercial substrate, and interaction between the two factors.

\begin{tabular}{|c|c|c|c|c|}
\hline \multirow{2}{*}{$\begin{array}{l}\text { Parâmetros avaliados - dias após a } \\
\text { semeadura }^{(1)}\end{array}$} & \multicolumn{3}{|c|}{ Probabilidade do teste $\mathrm{F}$} & \multirow{2}{*}{$\begin{array}{l}\mathbf{C V}^{(2)} \\
(\%)\end{array}$} \\
\hline & Espécie & $\begin{array}{c}\text { Proporção do } \\
\text { CARS ao SC } \\
\end{array}$ & $\begin{array}{c}\text { Interação } \\
\text { (CARS x SC) }\end{array}$ & \\
\hline Emergência (\%) - 36 dias & $0,0000 *$ & 0,1068 & 0,1008 & 8,3 \\
\hline Altura $(\mathrm{cm})-65$ dias & $0,0000 *$ & 0,0056 & 0,6494 & 12,2 \\
\hline Altura $(\mathrm{cm})-94$ dias & $0,0000 *$ & 0,9332 & 0,9645 & 10,0 \\
\hline Altura $(\mathrm{cm})-128$ dias & $0,0000 *$ & 0,7384 & 0,9178 & 11,6 \\
\hline $\mathrm{DC}(\mathrm{mm})-128$ dias & $0,0000 *$ & 0,2594 & 0,3007 & 10,8 \\
\hline MSPA (g planta $\left.{ }^{-1}\right)-128$ dias & $0,0000 *$ & 0,1331 & 0,2131 & 11,0 \\
\hline $\operatorname{MSR}\left(\mathrm{g}\right.$ planta $\left.^{-1}\right)-128$ dias & $0,0000 *$ & 0,1115 & 0,1380 & 14,8 \\
\hline Relação H/DC - 128 dias & $0,0000 *$ & 0,5077 & 0,9241 & 15,1 \\
\hline Relação H/MSPA - 128 dias & $0,0000 *$ & 0,4773 & 0,7081 & 12,1 \\
\hline Relação MSPA/MSR - 128 dias & $0,0000 *$ & 0,3978 & 0,1870 & 16,1 \\
\hline IQD - 128 dias & $0,0000 *$ & 0,1130 & 0,2026 & 16,3 \\
\hline
\end{tabular}

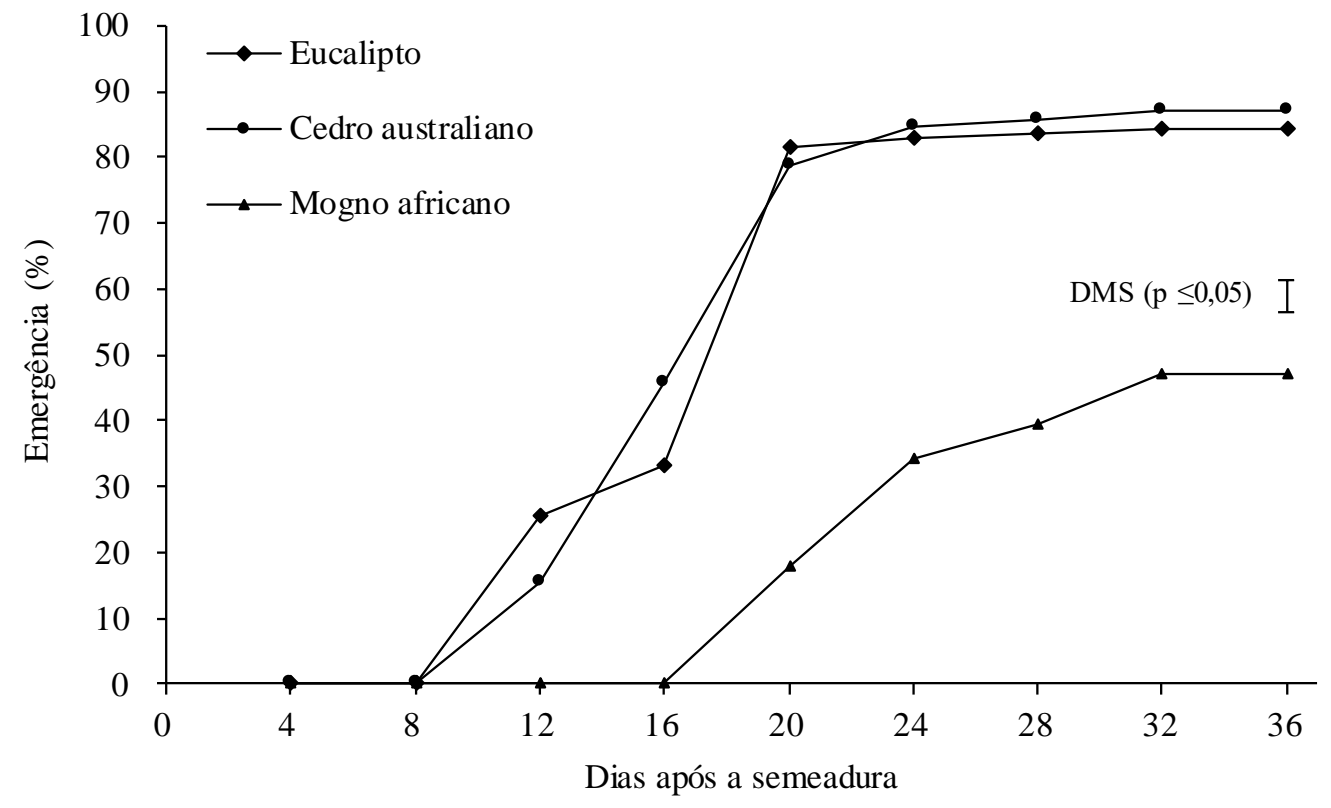

Figura 1. Percentual de emergência de plântulas de eucalipto, cedro australiano e mogno africano no período de 36 dias da semeadura. Média de cinco proporções de composto de dejetos de suínos adicionadas ao substrato comercial.

Figure 1. Emergence percentage of the seedlings of eucalyptus, Australian cedar and African mahogany seeds in the 36-day of sowing period. Average of five proportions of swine wastewater compound added to the commercial substrate. 


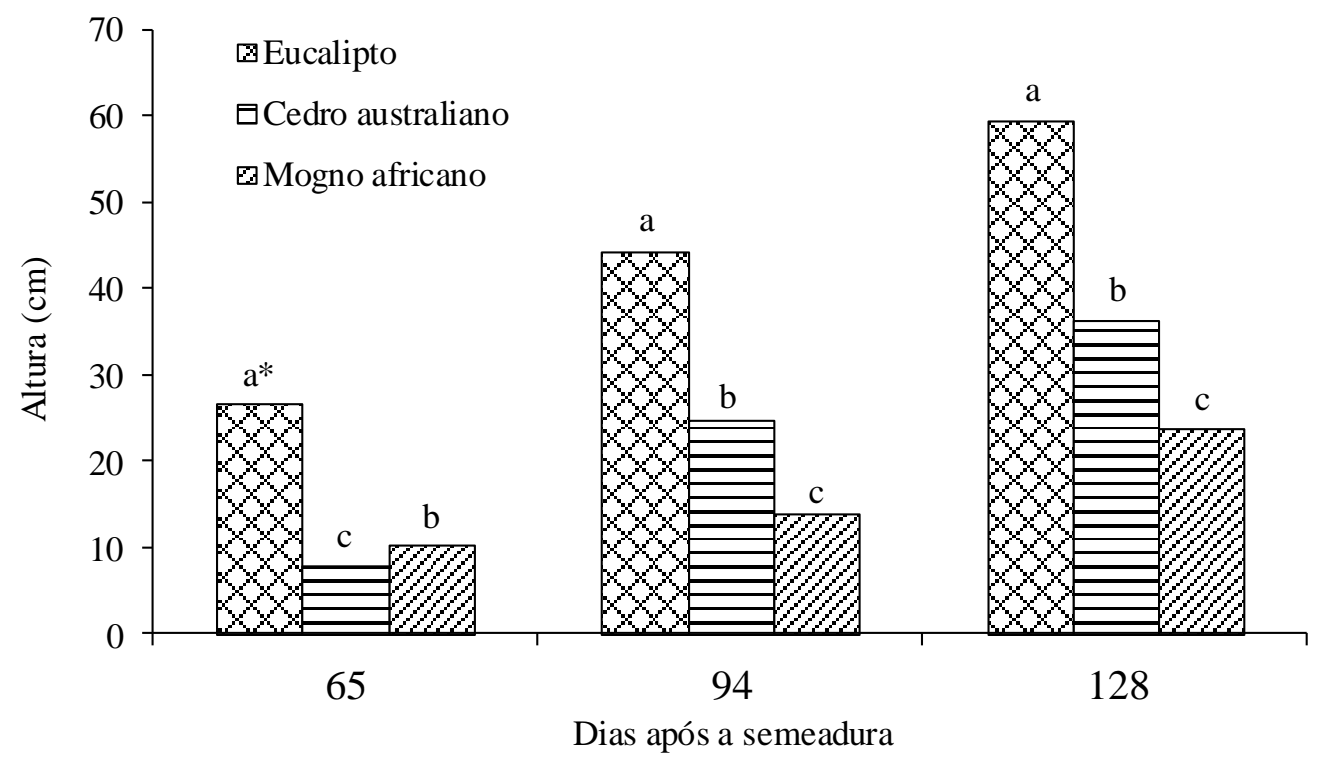

Figura 2. Altura das mudas de eucalipto, cedro australiano e mogno africano no período de 128 dias da semeadura. Média de cinco proporções de composto de dejetos de suínos adicionadas ao substrato comercial. *Médias não seguidas pela mesma letra, em cada época, diferem pelo teste de Tukey $(\mathrm{p} \leq 0,05)$.

Figure 2. Eucalyptus, Australian cedar and African mahogany seedlings height in the 128-day of sowing period. Average of five proportions of swine wastewater compound added to the commercial substrate. *Averages not followed by the same letter, at each time, differ by the Tukey test $(\mathrm{p} \leq 0.05)$

A qualidade das mudas, avaliadas aos 128 dias da semeadura, por meio das relações H/DC, H/MSPA e MSPA/MSR, foi significativamente diferente entre as espécies florestais (Tabela 3). $\mathrm{O}$ eucalipto apresentou a maior relação H/DC, seguido do cedro australiano e mogno africano, com valores de 14,96; 6,46 e 5,48, respectivamente. A relação H/MSPA teve a mesma ordem de sequência, com valores respectivos de 11,41; 8,16 e 4,46. O mogno africano foi a espécie que teve a maior relação MSPA/MSR, seguido do eucalipto e do cedro australiano, com valores de 4,73; 3,66 e 1,97, respectivamente.

A qualidade das mudas, avaliada pelo IQD aos 128 dias da semeadura, foi significativamente superior no cedro australiano, com valor de 0,80 (Tabela 3). No mogno africano e no eucalipto, os valores foram de 0,63 e 0,35 , respectivamente.

Tabela 3. Diâmetro do colo (DC), massa seca da parte aérea (MSPA) e massa seca radicular (MSR), relação entre altura e diâmetro de colo (H/DC), relação entre altura e massa seca da parte aérea (H/MSPA), relação entre massa seca da parte aérea e massa seca radicular (MSPA/MSR) e índice de qualidade de Dickson (IQD) das mudas de do eucalipto, cedro australiano e mogno africano aos 128 dias após a semeadura. Médias de cinco proporções de composto de dejetos de suínos adicionadas ao substrato comercial.

Table 3. Stem diameter, aerial dry mass and root dry mass, relation between height and stem diameter, relation between height and dry mass of shoot, and Dickson quality index of eucalyptus, Australian cedar and African mahogany seedlings at 128 days after sowing. Averages of five proportions of swine wastewater compound added to the commercial substrate.

\begin{tabular}{lccc}
\hline \multirow{2}{*}{ Parâmetros avaliados } & \multicolumn{3}{c}{ Espécies florestais } \\
\cline { 2 - 4 } & Eucalipto & Cedro australiano & Mogno africano \\
\hline DC $(m m)$ & $4,01 \mathrm{~b}^{(1)}$ & $5,62 \mathrm{a}$ & $4,33 \mathrm{~b}$ \\
MSPA $\left(\mathrm{g} \mathrm{planta}^{-1}\right)$ & $5,19 \mathrm{a}$ & $4,44 \mathrm{~b}$ & $5,29 \mathrm{a}$ \\
MSR $\left(\mathrm{g} \mathrm{planta}{ }^{-1}\right)$ & $1,42 \mathrm{~b}$ & $2,26 \mathrm{a}$ & $1,12 \mathrm{c}$ \\
Relação H/DC & $14,96 \mathrm{a}$ & $6,46 \mathrm{~b}$ & $5,48 \mathrm{~b}$ \\
Relação H/MSPA & $11,41 \mathrm{a}$ & $8,16 \mathrm{~b}$ & $4,46 \mathrm{c}$ \\
Relação MSPA/MSR & $3,66 \mathrm{~b}$ & $1,97 \mathrm{c}$ & $4,73 \mathrm{a}$ \\
IQD & $0,35 \mathrm{c}$ & $0,80 \mathrm{a}$ & $0,63 \mathrm{~b}$ \\
\hline
\end{tabular}

${ }^{(1)}$ Médias não seguidas pela mesma letra, na linha, diferem pelo teste de Tukey a 5\% de probabilidade de erro. 


\section{DISCUSSÃO}

A adição do CARS ao SC não afetou a emergência das plântulas, o crescimento e a qualidade das mudas nas três espécies florestais, provavelmente devido às condições físicas adequadas dos dois compostos utilizados na mistura para a composição dos substratos. Os baixos e médios valores de densidade dos substratos $(0,19$ e $\left.0,29 \mathrm{Mg} \mathrm{m}^{-3}\right)$ proporcionaram altos volumes de porosidade total $\left(0,77 \mathrm{e} 0,86 \mathrm{~m} \mathrm{~m}^{-3}\right)$, independente da quantidade de CARS adicionada ao SC. Os substratos usados na produção de mudas de espécies florestais, conforme valores estabelecidos por Gonçalves \& Poggiani (1996), citados por Delarmelina et al. (2014), apresentam baixa e média densidade, quando menor que $0,25 \mathrm{Mg} \mathrm{m}^{-3}$ e entre 0,25 e $0,50 \mathrm{Mg} \mathrm{m}^{-3}$, respectivamente, e alta porosidade, quando superior a $0,75 \mathrm{~m} \mathrm{~m}^{-3}$. Como o CARS apresenta maior porosidade total em comparação ao SC, mostra-se o potencial de uso deste material na composição de substratos, tanto na forma individual quanto em mistura com outros materiais (BRUGNARA et al., 2014; DA ROS et al., 2017).

A alta porosidade é um atributo condicionante do substrato, que possibilita fornecer oxigênio e água para o crescimento radicular. Os poros maiores presentes no substrato são responsáveis pelo arejamento (macroporos) e os menores (microporos) pela retenção de água no interior dos tubetes. O ideal é o balanço entre $50 \%$ de proporção de micro e de macroporos em relação à porosidade total (ZORZETO et al., 2014). No presente estudo, essa proporção foi próxima a $50 \%$, indicando que todos os substratos utilizados para produção de mudas das espécies florestais apresentaram adequado suprimento de oxigênio e de água para a germinação e crescimento das mudas. Suguino et al. (2011) destacam que o substrato deve proporcionar retenção de água suficiente para permitir a germinação e, quando saturado, manter quantidades adequadas de espaços porosos para facilitar o fornecimento de oxigênio, que é indispensável no processo de germinação das sementes e crescimento das mudas.

A retenção de água pelos microporos é importante para mantê-la próxima às sementes e facilitar a sua absorção durante o processo de germinação. No entanto, esse valor deve estar correlacionado com o espaço de aeração disponibilizado imediatamente após a saturação dos poros com água da irrigação para não limitar o fornecimento de oxigênio. Assim, a capacidade de absorção de água pelas sementes depende da retenção de água e da aeração do substrato, que é afetado pelo equilíbrio entre a macro e a microporosidade (SUGUINO et al., 2011; ZORZETO et al., 2014). Em sistemas de produção de mudas, quanto menor o recipiente, mais difícil será a adequação do equilíbrio entre macro e microporosidade, pois os espaços de aeração são ocupados pelas raízes à medida que aumenta o crescimento do sistema radicular (SUGUINO et al., 2011). Os autores ainda relatam que, normalmente, há limitação de espaço para a expansão das raízes em sistema de produção de mudas com tubetes, exigindo que o substrato seja capaz de manter um volume de água facilmente disponível às plantas, sem comprometer o fornecimento de oxigênio. Nessa condição, a alta capacidade de aeração é fundamental para a escolha do substrato, pois a alta retenção de água pode reduzir a oxigenação das raízes e dificultar o crescimento das mudas.

$\mathrm{O}$ espaço de aeração ideal para substratos é entre 0,20 e $0,30 \mathrm{~m}^{3} \mathrm{~m}^{-3}$, como relatado pela literatura (DE BOODT et al., 1974, citado por VALERO et al., 2009). Observa-se que os valores encontrados em todos os tratamentos utilizados no presente estudo $\left(0,26\right.$ e $\left.0,30 \mathrm{~m}^{3} \mathrm{~m}^{-3}\right)$ estão dentro da faixa indicada pela literatura. Em um estudo com produção de mudas de maracujazeiro-amarelo (Passiflora edulis Sims f. flavicarpa), usando mistura de CARS ao SC da marca Tecnomax HF® (Brugnara et al., 2014), também não foi encontrada diferença no percentual de emergência de plântulas com valores de espaço de aeração entre 0,19 e $0,25 \mathrm{~m}^{3} \mathrm{~m}^{-3}$, semelhante ao do presente estudo. Isso indica que esse parâmetro foi adequado para as três espécies florestais estudadas, pois não restringiu a emergência das plântulas e o crescimento das mudas.

Com relação às propriedades físicas, a densidade, a porosidade total e o espaço de aeração são os atributos mais importantes para caracterizar os substratos e apresentaram correlação com as variáveis biométricas das mudas (KRATZ; WENDLING, 2013). A adequação destas características nos substratos para a produção de mudas é obtida, normalmente, com o uso de misturas de compostos orgânicos em diferentes proporções (DELARMELINA et al., 2014; DA ROS et al., 2015). No caso do uso de CARS, mostra-se que este pode ser usado isoladamente na produção de mudas de espécies florestais, sem necessidade de mistura com outros materiais. Essa constatação é importante, pois é uma alternativa para aproveitamento adequado destes compostos orgânicos gerados dentro das unidades de produção de suínos da região sul do Brasil.

A condutividade elétrica é outro atributo intrínseco do substrato que pode afetar a germinação das sementes e o crescimento das mudas (KRATZ et al., 2013). A avaliação do percentual de germinação é uma das formas mais comuns para quantificar a tolerância das plantas ao excesso de sais que podem estar presentes no substrato. No caso do presente estudo, a variação da condutividade elétrica, com valor de $1,0 \mathrm{dS} \mathrm{m}^{-1}$ no $\mathrm{SC}$ e de $1,5 \mathrm{dS} \mathrm{m} \mathrm{m}^{-1}$ no CARS, provavelmente não foi suficiente para que a maior concentração de sais nos substratos proveniente do CARS prejudicasse a emergência das plântulas e o crescimento das mudas das três espécies florestais estudadas, semelhante ao estudo de Kratz e Wendling (2013) com o Eucalyptus dunnii.

Em um estudo com produção de mudas de cedro australiano, Da Ros et al. (2017) encontraram menor potencial de crescimento de cedro australiano com o uso de CARS associado à adubação mineral, justificado pela

FLORESTA, Curitiba, PR, v. 48, n. 1, p. 103-112, jan./marc. 2018.

Da Ros. C. O. et al.

ISSN eletrônico 1982-4688

DOI: $10.5380 /$ rf.v48 i 1.53346 
maior condutividade elétrica $\left(5,2 \mathrm{dS} \mathrm{m}^{-1}\right)$ em comparação ao SC $\left(0,7 \mathrm{dS} \mathrm{m}^{-1}\right)$. Brugnara et al. (2014), usando misturas de CARS e SC na produção de mudas de maracujazeiro-amarelo com valores de condutividade elétrica entre 0,7 e $5,3 \mathrm{dS} \mathrm{m}^{-1}$, verificaram que a emergência das plântulas não foi afetada, mesmo com valor de condutividade elétrica semelhante ao encontrado por Da Ros et al. (2017). O efeito negativo da condutividade elétrica no crescimento de mudas é dependente da espécie florestal, como relatado por Mendonça et al. (2010), em espécies de eucalipto, e por Kratz et al. (2013), em Eucalyptus benthamii e Mimosa scabrella. No caso das espécies avaliadas no presente estudo, indica-se que a condutividade elétrica não é fator condicionante para o uso do CARS como substrato na produção das mudas, pois o percentual de emergência de plântulas e o crescimento das mudas não foram afetados pela adição do CARS ao SC. No entanto, estudos para delimitar níveis críticos de condutividade elétrica para estas espécies devem ser realizados para não comprometer o uso do CARS como substrato na produção de mudas.

A ausência de resposta no crescimento e na qualidade das mudas com a adição de CARS ao SC pode estar relacionada, além de à adequada condição física dos substratos, à disponibilidade de nutrientes, sejam pelos teores presentes no substrato ou adicionados via fertilizante mineral. Em todos os tratamentos, foi usada a mesma quantidade de fertilizante de liberação lenta (Osmocote $\left.{ }^{\circledR}\right)$, fórmula 15-9-12, na dose 7,0 $\mathrm{kg} \mathrm{m}^{3}$ de substrato. Essa adubação ocorreu para disponibilizar quantidades adequadas de nitrogênio, fósforo e potássio em todo o período de crescimento das mudas. Assim, a escolha da proporção mais adequada de CARS ao SC não foi feita com o objetivo de fornecer nutrientes via substrato, pois a maior parte dos nutrientes presentes no substrato foi perdida por lixiviação durante o período de produção de mudas em tubetes com quatro irrigações diárias.

O uso de fertilizantes de liberação lenta, ou fertirrigação, é necessário para proporcionar adequado crescimento e qualidade das mudas, mesmo em substrato com elevada disponibilidade de nutrientes. Estudos de produção de mudas em tubetes com irrigações diárias mostram que a taxa de lixiviação de nutrientes é alta e as perdas de nutrientes são proporcionais às suas quantidades presentes no substrato (DA ROS et al., 2017). Assim, a adequada produção de mudas em tubetes de pequeno volume está mais associada às condições físicas do que à quantidade de nutrientes presentes no substrato, principalmente quando disponibilizados via fertilizantes de liberação lenta.

Em estudo com produção de mudas de cedro australiano em pequenos tubetes $\left(100 \mathrm{~cm}^{3}\right)$, Da Ros et al. (2017) encontraram, quando não foi usado fertilizante mineral, maiores altura, diâmetro do colo e massa seca das mudas com o uso de substrato à base CARS, em comparação com o SC. No entanto, os autores verificaram que, além do incremento no crescimento das mudas, sua qualidade só foi adequada com o uso adicional de fertilizante mineral. No trabalho de Brugnara et al. (2014) com maracujazeiro-amarelo em vasos maiores $\left(1.200 \mathrm{~cm}^{3}\right)$, o uso de CARS ao SC proporcionou crescimento adequado às mudas com ausência de fertilizante mineral, sendo justificado pela maior quantidade de nutrientes presente no CARS e pela menor perda

Comparando as espécies florestais, o baixo percentual de emergência das plântulas do mogno africano pode estar relacionado às suas características intrínsecas, como tamanho, tempo de armazenamento e manejo de coleta e póscoleta das sementes (GODINHO et al., 2011). Essas características também influenciam na velocidade de germinação das espécies florestais, sendo que o eucalipto e cedro australiano iniciaram a emergência a partir de oito dias da semeadura, enquanto o mogno africano dobrou o tempo para início da emergência. O crescimento das mudas também é intrínseco à espécie florestal e pode afetar a qualidade das mudas no momento da implantação no campo.

A maior relação entre altura e diâmetro do colo (H/DC) e altura e massa seca da parte aérea (H/MSPA) nas mudas do eucalipto pode dificultar o pegamento após plantio no campo, pois, quanto menos lignificada a muda, menor a sua capacidade de sobrevivência em campo. O índice de qualidade de Dickson (IQD), que considera a robustez (H/DC) e o equilíbrio da distribuição da biomassa das mudas (MST, MSPA e MSR), também foi menor nas mudas do eucalipto, indicando baixa qualidade das mudas, independente da proporção de CARS adicionado ao SC. A adequação do tempo de cultivo das mudas é um fator que pode melhorar a sua qualidade para implantação no campo e, em conjunto com o CARS, pode ser objeto de estudos em futuros projetos de produção de mudas de espécies florestais.

\section{CONCLUSÕES}

- A substituição total ou parcial do substrato comercial por composto orgânico proveniente do tratamento da água residuária de suinocultura não alterou a emergência das plântulas, o crescimento e a qualidade das mudas das espécies florestais.

- O composto orgânico proveniente do tratamento da água residuária de suinocultura, obtido através de compostagem mecanizada, em substituição parcial ou total ao substrato comercial, é indicado para produção de mudas de eucalipto, de cedro australiano e de mogno africano. 


\section{AGRADECIMENTOS}

Os autores agradecem ao apoio financeiro do Fundo de Incentivo à Pesquisa (FIPE) da Universidade Federal de Santa Maria.

\section{REFERÊNCIAS}

ABRAF - Associação Brasileira de Produtores de Florestas Plantadas. Anuário estatístico da ABRAF 2013 ano base 2012. Brasília: ABRAF, 2013. 148p. Disponível em: <http://www.bibliotecaflorestal.ufv.br/handle/1 23456789/3910>. Acesso em: 28 de agosto de 2015.

ALVARES, C. A.; STAPE, J. L.; SENTElhAS, P. C.; MORAES GONÇALVES, J. L. de; SPAROVEK, G. Köppen's climate classification map for Brazil. Meteorologiesche Zeitschrift, v. 22, n. 6, p. 711-728, 2013.

BRASIL. Ministério da Agricultura, Pecuária e Abastecimento - MAPA. Secretaria de Defesa Agropecuária. Instrução Normativa no 17 de 21 de maio de 2007/ SDA - Secretaria de Defesa Agropecuária. Análise de Substratos e Condicionadores de Solos. Aprova os Métodos Analíticos Oficiais para Análise de Substratos e Condicionadores de Solos [online]. Diário Oficial da União, Brasília, DF, maio de 2007. Disponível em: <http:// sistemasweb.agricultura.gov.br/sislegis/action/detalhaAto. do?method=consultarLegislacaoFederal> . Acesso em: 09 mai 2016.

BRASIL. Ministério de Agricultura Pecuária e Abastecimento - MAPA. Instrução Normativa nº 25, de 23 de julho de 2009. Diário Oficial da União, Brasília, DF, vinte e oito de julho de 2009. Disponível em: <HTTP://sistemasweb.agricultura.gov.br/sislegis/action/detalhaAto.do?method=recuperarTextoAtoTematicaPort al\&codigoTematica=1229186>. Acesso em: 03 abr 2017.

BRUGNARA, E. C.; NESI, C. N.; VERONA, L. A. F. Cama de aviário e composto de dejetos suínos em substratos para mudas de maracujazeiro-amarelo. Revista Cientifica, Caldeira, v. 42, n. 3, p. 242-251, 2014.

DA ROS, C. O.; REX, F. E.; RIBEIRO, I. R.; KAFER, P. S.; RODRIGUES, A. C.; SILVA, R. F.; SOMAVILLA, L. Uso de substrato compostado na produção de mudas de Eucalyptus dunnii e Cordia trichotoma. Floresta e Ambiente, Rio de Janeiro, v. 22, n. 4, p. 549-558, 2015.

DA ROS, C. O.; SILVESTRIN, T. B.; SOMAVILLA, L.; PERRANDO, E. R.; SILVA, R. F. Perdas de nutrientes por lixiviação na produção de mudas de cedro australiano. Floresta e Ambiente, Rio de Janeiro, v. 24, n. e2016008127, 2017.

DELARMElinA, W. M.; CALDEIRA, M. V. W.; FARIA, J. C. T.; GONÇALVES, E. O.; ROCHA, R. L. F. Diferentes substratos para a produção de mudas de Sesbania virgata. Floresta e Ambiente, Rio de Janeiro, v. 21 , n. 2, p. 224-233, 2014.

DICKSON, A.; LEAF, A.L.; HOSNER, J.F. Quality appraisal of white spruce and white pine seedling stock in nurseries. Forest Chronicle, v. 36, p.10-13, 1960.

EMBRAPA - Empresa Brasileira de Pesquisa Agropecuária, Centro Nacional de Pesquisas de Solos. Manual de métodos de análises de solo. Rio de Janeiro: Embrapa Solos, 2 ed. 2011, 230 p.

GODINHO, M. A. S.; MANTOVANI-ALVARENGA, E.; VIEIRA, M. F. Germinação e qualidade de sementes de Adenostemma brasilianum (PERS.) CASS., asteraceae nativa de sub-bosque de floresta atlântica. Revista Árvore, Viçosa, v. 35, n. 6, p. 1197-1205, 2011.

KRATZ, D.; WENDLING, I. Produção de mudas de Eucalyptus dunnii em substratos renováveis. Floresta, Curitiba, v. 43, n. 1, p. 125-136, 2013.

KRATZ, D.; WENDLING, I.; NOGUEIRA, A. C.; SOUZA, P. V. D. Utilização de resíduos urbanos e agroflorestais para produção de mudas de Eucalyptus benthamii e Mimosa scabrella. Floresta e Ambiente, Rio de Janeiro, v. 20, n. 4, p. 530-537, 2013.

MENDONÇA, A. V. R.; CARNEIRO, J. G de; FREITAS, T. A. S de; BARROSO, D. G. Características fisiológicas de mudas de Eucalyptus spp submetidas a estresse salino. Ciência Florestal, Santa Maria, v. 20, n. 2 , p. 255-267, 2010.

MENDONÇA, V.; MELO, J. K. H.; MENDONÇA, L. F. M.; LEITE, G. A.; PEREIRA, E. C. Avaliação de diferentes substratos na produção de porta enxertos de tamarindeiro. Revista Caatinga, Mossoró, v. 27, n. 1, p. 60-66, 2014. 
MUNIZ, C. O.; LÔBO, L. M.; FERNANDES, F. P. R.; FERREIRA, E. M.; BRASIL, E. P. F. Efeito de diferentes adubos NPK no processo de produção de mudas de Eucalipto. Enciclopédia Biosfera, Goiânia; v. 9, n. 17, p. 1162 $-1168,2013$.

PINHEIRO, A. L.; COUTO, L.; PINHEIRO, D. T.; BRUNETTA, J. M. F. C. Ecologia, silvicultura e tecnologia de utilização dos mognos-africanos (Khaya spp.). Viçosa: Sociedade Brasileira de Agrossilvicultura, 2011, 102 p.

SCHAFER, G.; SOUZA, P. V. D. de; FIOR, C. S. Um panorama das propriedades físicas e químicas de substratos utilizados em horticultura no sul do Brasil. Ornamental Horticulture, Campinas, v. 21, n. 3, p. 299-306, 2015.

SERPA FILHO, R.; SEHNEM, S.; CERICATO, A.; SANTOS, S. JR., FISCHER, A. Compostagem de dejetos de suínos. Revista em Agronegócio e Meio Ambiente, Maringá, v. 6, n. 1, p. 47-78, 2013.

SILVA, F. C. Manual de análises químicas de solos, plantas e fertilizantes. Brasília: Embrapa Informação Tecnológica, 2 ed. 2009, 627 p.

SOUZA, P. L. T. de; VIEIRA, L. R.; BOLIGON, A. A.; VESTENA, S. Produção e qualidade de mudas de Eugenia involucrata DC. em diferentes substratos. Revista Biociências, Taubaté, v. 21, n. 1, p. 100-108, 2015.

SUGUINO, E.; MARTINS, A. N.; MINAMI, K.; NARITA, N.; PERDONÁ, M. J. Efeito da porosidade do substrato casca de pínus no desenvolvimento de mudas de grumixameira. Revista Brasileira de Fruticultura, Jaboticabal, v. 33, n.spe 1, p. 643-648, 2011.

TRAZZI, P. A.; CALDEIRA, M. V. W.; PASSOS, R. R.; GONÇALVES, E. O. 2013. Substratos de origem orgânica para produção de mudas de teca (Tectona grandis Linn. F.). Ciência Florestal, Santa Maria, v. 23, n. 3, p. 401-409, 2013.

VALERO, R. M. M.; MATSURA, E. E.; SOUZA, A. L. de. Caracterização física de dois substratos orgânicos para plantas e a estimativa da umidade por meio da reflectometria no domínio do tempo. Ciência Rural, Santa Maria, v. 39, n. 2, p. 571-574, 2009.

VILELA, E. S.; STEHLING, E. C. Recomendações de plantio para cedro australiano. Campo Belo: Bela Vista Florestal, Versão 1.2. 2012, 23p.

ZORZETO, T. Q.; DECHEN, S. C. F.; ABREU, M. F. DE; FERNANDES JÚNIOR, F. Caracterização física de substratos para plantas. Bragantia, Campinas, v. 73, n. 3, p. 300-311, 2014. 